\title{
Photolysis Kinetics, Mechanisms, and Pathways of Tetrabromobisphenol A in Water under Simulated Solar Light Irradiation
}

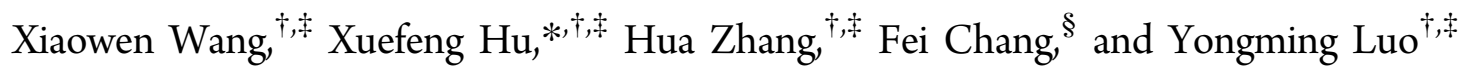 \\ ${ }^{\dagger}$ Key Laboratory of Coastal Environmental Processes and Ecological Remediation, Yantai Institute of Coastal Zone Research, Chinese \\ Academy of Sciences, Yantai, Shandong 264003, P.R. China \\ ${ }^{\ddagger}$ University of Chinese Academy of Sciences, Beijing 100049, P.R. China \\ ${ }^{\S}$ School of Environment and Architecture, University of Shanghai for Science and Technology, Shanghai 200093, P.R. China
}

Supporting Information

\begin{abstract}
The photolysis of tetrabromobisphenol A (TBBPA) in aqueous solution under simulated solar light irradiation was studied under different conditions to find out mechanisms and pathways that control the transformation of TBBPA during photoreaction. Particular attention was paid to the identification of intermediates and elucidation of the photolysis mechanism of TBBPA by UPLC, LC/MS, FT-ICR-MS, NMR, ESR, and stable isotope techniques $\left({ }^{13} \mathrm{C}\right.$ and $\left.{ }^{18} \mathrm{O}\right)$. The results showed that the photolysis of TBBPA could occur under simulated solar light irradiation in both aerated and deaerated conditions. A magnetic isotope effect (MIE)hydrolysis transformation was proposed as the predominant pathway for TBBPA photolysis in both cases. 2,6-Dibromophenol and two isopropylphenol derivatives were identified as photooxidation products of TBBPA by singlet oxygen. Reductive debromination products tribromobisphenol A and dibromobisphenol A were also observed. This is the first report of a photolysis pathway involving the formation of hydroxyl-tribromobisphenol A.
\end{abstract}

\section{INTRODUCTION}

Tetrabromobisphenol A (TBBPA) is extensively used in plastics, textiles, and electronics as a commercial brominated flame retardant to improve fire safety. ${ }^{1-3}$ Release of TBBPA to the environment occurs during manufacturing, recycling, and disposal of various textiles and solid waste materials. ${ }^{4}$ For instance, ТВBPA concentrations were up to $540 \mathrm{ng} / \mathrm{L}$ in dumps dialyzates and up to $620 \mathrm{ng} / \mathrm{L}$ in industrial landfill leachates as reported in Japan. ${ }^{5,6}$ TBBPA was found in human tissues, ${ }^{7}$ maternal and cord serum, breast milk in women, ${ }^{8}$ and serum from an exposed and general population. ${ }^{9,10}$ Researchers suggest that TBBPA is a potentially persistent, bioaccumulative, and toxic (PBT) compound. ${ }^{1}$ It has been identified as an environmental endocrine disruptor and reported to display low but multiple hormonal activities. ${ }^{11}$

Due to the extensive use, bioaccumulation, toxicity, and potential hazard of TBBPA, it is urgent to investigate its transformation in water and develop effective decontamination methods. Both biotic and abiotic methods have been developed to remove TBBPA from the aquatic environment. ${ }^{12-19}$ Most reactions under aerobic conditions were performed in the presence of catalysts, aiming to develop more effective methods with high debromination and TOC removal efficiency. Photolysis is one of the main abiotic degradation pathways of TBBPA and may affect its fate and ecological risk in the natural environment. The degradation of TBBPA was reported to involve different photochemical processes. ${ }^{20-28}$ TBBPA could be degraded by UV irradiation, ${ }^{20,21}$ photocatalytic oxidation $\left(\mathrm{TiO}_{2}{ }^{22,23} \mathrm{Ag} / \mathrm{Bi}_{5} \mathrm{Nb}_{3} \mathrm{O}_{15}{ }^{24} \mathrm{BiOBr},{ }^{25}\right.$ titanomagnetite, ${ }^{26}$ [Mn$(\mathrm{VII})]^{27}$ ), and photosensitized oxidation. ${ }^{28,29}$ In these photoreactions, photogenerated electrons and reactive oxygen species (ROS) were responsible for its degradation. Debromination and beta scission were proposed as two major pathways. ${ }^{26}$ However, the mechanism of direct photochemical transformation independent of the function of ROS was overlooked.

In this work, phototransformation of TBBPA in water under both aerobic and anaerobic conditions was investigated. Kinetic isotope effects (KIE) as a powerful tool was used to determine the reaction mechanism. Together with the ${ }^{18} \mathrm{O}$ isotope tracing technique, we proposed the TBBPA photolysis pathway that is different from previous studies. It was our aim to investigate (1) the possible photolysis pathways of TBBPA in water; (2) the validity of stable isotope techniques and products analysis combined for the degradation pathway differentiation; and (3) the active species responsible for the photolysis of TBBPA.

Received: March 5, 2015

Revised: $\quad$ May 1, 2015

Accepted: May 3, 2015

Published: May 4, 2015 
This study should be helpful in better understanding the photochemical behavior of aromatic bromide in aquatic environments.

\section{MATERIALS AND METHODS}

Materials and Chemicals. Tetrabromobisphenol A (purity 99\%) was obtained from the Dr. Ehrenstofer Germany. $\mathrm{H}_{2}{ }^{18} \mathrm{O}$ $\left({ }^{18} \mathrm{O}>97 \%\right)$ was purchased from the Shanghai Research Institute of Chemical Industry (SRICI). Reagents $\mathrm{NaCl}$, $\mathrm{Na}_{2} \mathrm{SO}_{4}, \mathrm{Na}_{2} \mathrm{CO}_{3}, \mathrm{Fe}\left(\mathrm{ClO}_{4}\right) \cdot 6 \mathrm{H}_{2} \mathrm{O}, \mathrm{HClO}_{4}, \mathrm{NaOH}$, rose bengal, $\mathrm{NaN}_{3}$, furfuryl alcohol, and fulvic acid were purchased from the China National Medicines Co. (China), and HPLCgrade methanol was obtained from Shanghai Xingke Biochemical Co. (China). All experimental solutions were prepared by dissolving reagents directly in ultrapure water. All stock solutions were refrigerated after preparation.

Photochemical Experiments. Photochemical experiments were conducted in a photochemical reaction chamber XPA-7 (350W-Xe, Xujiang, China, $\lambda>290 \mathrm{~nm}$ ) to simulate solar light. Irradiation of aqueous solutions $(50 \mathrm{~mL})$ was carried out in quartz glass reaction cells, which were positioned at a distance of $5.5 \mathrm{~cm}$ to the lamp center. The light intensity impinging on the solutions was $20 \mathrm{~mW} / \mathrm{cm}^{2}$ as measured with a radiometer (CEL-NP2000, Beijing Aulight Co. China). The initial TBBPA concentrations were $10^{-4} \mathrm{M}$. The initial $\mathrm{pHs}$ of the aqueous solutions were fixed at 8.0 by adjusting the solutions with $\mathrm{NaOH}$ and $\mathrm{HClO}_{4}$ and were not controlled during the course of the reaction. At given reaction time intervals, samples were taken out and analyzed by ultra performance liquid chromatography (UPLC) (Figure S1). Each experiment was conducted at least twice with relative errors less than $5 \%$. The deaerated experiment was done under ultrapure $\mathrm{N}_{2}$ atmosphere.

Sample Pretreatment and Instrument Analysis Methods. The concentration of TBBPA in the reaction process was measured by UPLC (Waters, ACQUITY UPLC H-Class, USA) fitted with a C18 column $(2.1 \times 50 \mathrm{~mm}, 1.7 \mu \mathrm{m})$. The mobile phase composition was methanol- $0.2 \%$ acetic acid (70:30, V/ $\mathrm{V}$ ) at a flow rate of $0.2 \mathrm{~mL} / \mathrm{min}$. Samples were analyzed with a photodiode array (PDA) detector at a wavelength of $210 \mathrm{~nm}$. Solid phase extraction (SPE) was optimized as the primary extraction and cleaning procedure for all water samples for liquid chromatography/mass spectrometry (LC/MS) and carbon isotope analysis. After having been preconditioned by $10 \mathrm{~mL}$ of methanol and $10 \mathrm{~mL}$ of purified water, $50 \mathrm{~mL}$ of sample was loaded onto the $\mathrm{C} 18$ cartridge at a rate of $5 \mathrm{~mL} /$ $\mathrm{min}$, and the cartridges were subsequently eluted with $9 \mathrm{~mL}$ of methanol. The elution was then concentrated to ca. $1 \mathrm{~mL}$ by rotary evaporation. The LC/MS methods for analyzing photolysis products of TBBPA was performed using a LCQ Fleet (Thermo Fisher Scientific, USA) equipped with a Waters SunFireTM-C18 column $(4.6 \mathrm{~mm} \times 250 \mathrm{~mm}, 5 \mu \mathrm{m})$. Electron spray ionization (ESI) was performed with a spray voltage set at $5000 \mathrm{~V}$; sheath gas flow rate and aux gas flow rate and capillary temperature were set at $30 \mathrm{arb}, 10 \mathrm{arb}$, and $300{ }^{\circ} \mathrm{C}$, respectively. The ${ }^{18} \mathrm{O}$ isotopic tracer experiment was conducted in $\mathrm{H}_{2} \mathrm{O}^{18}$, and the sample was analyzed by LC/MS. The isotopic proportion of the parent peak or the fragment ion in the observed MS matches excellently the simulated spectra using the Chemdraw software. The electron spin resonance (ESR) technique was used to detect radicals on a Bruker (ESP $300 \mathrm{E})$ spectrometer equipped with a $355 \mathrm{~nm}$ laser. The ESR settings were modulation amplitude $1.94 \mathrm{G}$ and microwave frequency $9.75 \mathrm{GHz}$.

Stable carbon isotope ratios were determined by a stable isotope mass spectrometer (MAT253, Thermo Fisher). Spectra were obtained with a gas chromatograph (GC), equipped with a DB-5 MS capillary column $(30 \mathrm{~m} \times 0.25 \mathrm{~mm}, 0.25 \mu \mathrm{m})$. The GC column was operated in a temperature program with an initial temperature of $50{ }^{\circ} \mathrm{C}$ held for $4 \mathrm{~min}$, ramp first to $80{ }^{\circ} \mathrm{C}$ with a $10^{\circ} \mathrm{C} / \mathrm{min}$ rate and held at the temperature for $2 \mathrm{~min}$, then to $280{ }^{\circ} \mathrm{C}$ with a $10{ }^{\circ} \mathrm{C} / \mathrm{min}$ rate and held at the temperature for $15 \mathrm{~min}$. The combustion oven was held at 1000 ${ }^{\circ} \mathrm{C}$. Calibration of carbon isotope composition of $\mathrm{CO}_{2}$ gas was performed against international standard IAEA-600, Caffeine (Max-Planck-Institute for Biogeochemistry) and reported in per mil (\%o) relative to Vienna-Pee Dee Belemnite (VPDB). $\delta^{13} \mathrm{C}_{\mathrm{VPDB}}$ values of the analyses were measured against internal laboratory standard $\mathrm{CO}_{2}$ gas.

Hydroxyl-tribromobisphenol A, one of the phototransformation intermediates, was separated using preparative chromatography and characterized by Fourier transform ion cyclotron resonance mass spectrometry (FT-ICR-MS) (SolariX, Bruker, Germany) and ${ }^{1} \mathrm{H}$ nuclear magnetic resonance (NMR) (Bruker Avance $500 \mathrm{MHz}$ NMR). FT-ICR-MS (Figure S2): $\mathrm{m} / \mathrm{z}$ 476.834204 [ $\left.\mathrm{M}^{-}\right]$, calcd for $\mathrm{C}_{15} \mathrm{H}_{12} \mathrm{Br}_{3} \mathrm{O}_{3}$ ). ${ }^{1} \mathrm{H}$ NMR (in 500 $\mathrm{MHz}, \mathrm{DMSO}-d_{6}$, Figure S3) $\delta(\mathrm{ppm}): 9.84(\mathrm{OH}, \mathrm{s}), 7.19(\mathrm{H} 2$ and $\mathrm{H} 6, \mathrm{~s}), 6.75\left(\mathrm{H}^{\prime}\right), 6.53\left(\mathrm{H}^{\prime}\right), 1.49\left(\mathrm{CH}_{3}, \mathrm{~s}\right)$.

\section{RESULTS AND DISCUSSION}

ROS Analysis. It was reported that dissolved oxygen in water could participate in phototransformation of organic compounds by producing ROS. ${ }^{30,31}$ To determine the active substance in ROS-induced phototransformation of TBBPA, several ROS initiator and trappers were added to reaction solutions. Photolysis of TBBPA in the presence of rose bengal $(\mathrm{RB})$, methanol (MEH), furfuryl alcohol (FA), and sodium azide $\left(\mathrm{NaN}_{3}\right)$ was examined, as shown in Figure 1. A pseudofirst-order kinetic model was used to calculate TBBPA degradation rate given in Table S1.

No significant change was found in the reaction by adding methanol as trapper of hydroxyl radical. It is clearly seen that hydroxyl radicals exerted no significant effect on the transformation of TBBPA. TBBPA photolysis rates were suppressed in the presence of furfuryl alcohol and sodium azide and accelerated in the presence of $\mathrm{RB}$ compared with that in pure

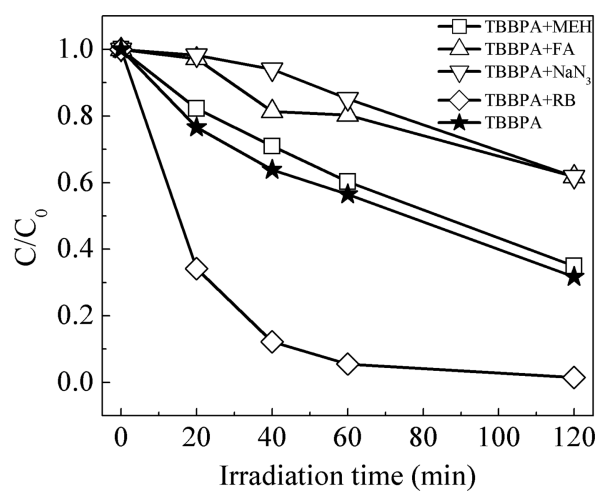

Figure 1. TBBPA photolysis in the presence of methanol (MEH), furfuryl alcohol (FA), sodium azide $\left(\mathrm{NaN}_{3}\right)$, and rose bengal (RB). Reactions were conducted with initial TBBPA concentration of 0.1 $\mathrm{mmol} / \mathrm{L}(\mathrm{pH}=8.0)$. 

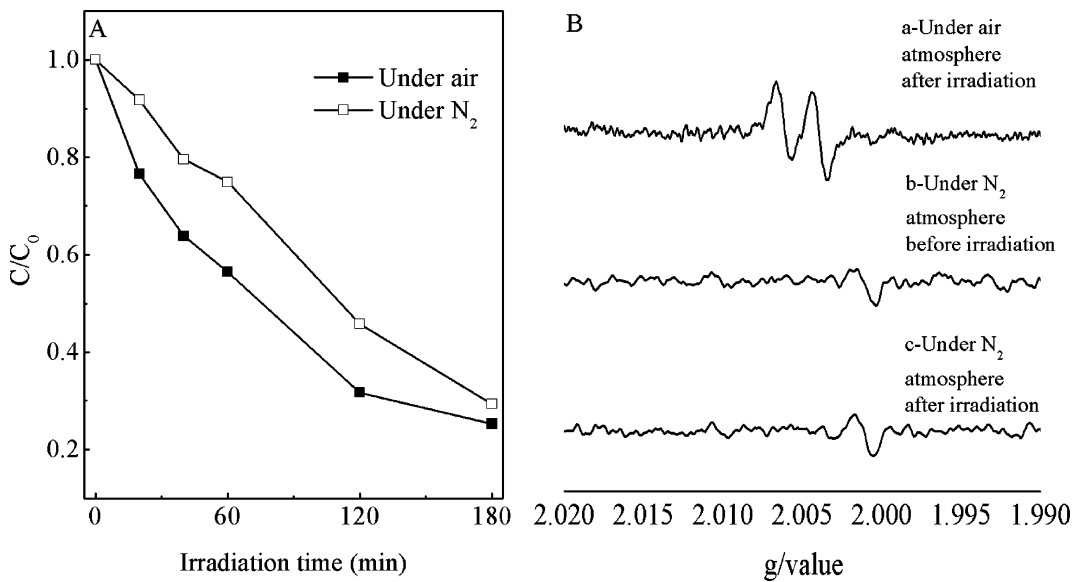

Figure 2. A) Comparison of TBBPA photolysis under air and $\mathrm{N}_{2}$ atmosphere; $\mathrm{B}$ ) ESR spectrum observed during irradiation of TBBPA (0.1 mmol/ L) solution $(\mathrm{pH}=8.0)$. The spectrum under air atmosphere contains an organic radical $\left(g=2.0054, a_{\mathrm{H}}=4.0 \mathrm{G}\right)$. No additive in these reactions.

water. The results suggest that TBBPA photolysis involves absorption of light and singlet molecular oxygen. In the TBBPA solution without ROS initiator and trappers, TBBPA acted as a singlet oxygen sensitizer and caused its own degradation. The TBBPA and RB solution was irradiated through an optical filter $(\lambda>400 \mathrm{~nm})$ using the same light source. Here, the visible light was used to stimulate $\mathrm{RB}$ but not TBBPA to generate singlet oxygen. The degradation of TBBPA by ${ }^{1} \mathrm{O}_{2}$ was well-studied by Bilski and will be described in the following part. ${ }^{28}$

Interestingly, TBBPA exhibited significant photolysis under $\mathrm{N}_{2}$ atmosphere with a rate slightly lower than that under air atmosphere, as shown in Figure 2A. The results indicated that dissolved oxygen was not required for the photolysis of TBBPA. In other words, TBBPA could undergo direct photolysis independent of ${ }^{1} \mathrm{O}_{2}$ oxidation. In air atmosphere, a strong ESR signal $\left(g=2.0054, a_{\mathrm{H}}=4.0 \mathrm{G}\right)$ was observed (under air, Figure 2B-a) when TBBPA solution was irradiated $(\lambda=355 \mathrm{~nm})$. However, generation of this radical was completely inhibited in the deoxygenated solution $\left(\mathrm{N}_{2}\right.$ atmosphere, Figure 2B-b and 2B-c), confirming that its generation was essentially $\mathrm{O}_{2}$-dependent. The doublets radical signal indicated the coupling is due to the interaction between the unpaired electron with a single hydrogen atom. Bilski et al. $^{28}$ have reported the similar radical signal and suggested that the substituted products of the 2,6-dibromo- $p$-benzosemiquinone radical at the 3-position by EPR silent groups ( $-\mathrm{OH}$ or $-\mathrm{Br}$ ) might be responsible. The ESR results indicated that the direct photolysis pathway did not involve the radical intermediate as observed in the ${ }^{1} \mathrm{O}_{2}$ oxidation pathway. Different reaction pathways might result in different products, and identification of those products facilitated a better understanding of the reaction mechanism.

Products Identification. Photolysis products were identified by LC/MS and listed in Table 1. Some products were not identified because of their low concentration in the reaction mixture. Products (2), (5), (6), (7), and (8) had been observed in oxidation/reduction reaction systems in earlier studies. ${ }^{19,20}$ Products (3) and (4) were observed for the first time in the photodegradation system. Concentration of product (3) increased quickly during the first hour of reaction and then decreased slowly (Figure 3). Correspondingly, concentration of product (4) increased slowly during the first hour but then increased quickly. This evidenced that product (4) should be produced from consecutive hydroxylation of product (3).
The newly observed degradation product, hydroxyl-tribromobisphenol A (product (3)), was investigated carefully. Its molecular formula was determined as $\mathrm{C}_{15} \mathrm{H}_{13} \mathrm{Br}_{3} \mathrm{O}_{3}$ by FT-ICRMS ( $m / z 476.834204\left[\mathrm{M}^{-}\right]$, calcd for $\mathrm{C}_{15} \mathrm{H}_{12} \mathrm{Br}_{3} \mathrm{O}_{3}$, Figure S2), suggesting eight degrees of unsaturation. The ${ }^{1} \mathrm{H}$ NMR spectrum (in $500 \mathrm{MHz}$, DMSO- $d_{6}$, Figure S3) displayed four $\mathrm{H}$ on the benzene ring with three values of chemical shift (7.19, 6.75 , and $6.53 \mathrm{ppm}$ ) and a broad singlet attributed to the $\mathrm{H}$ of the hydroxyl group $(9.84 \mathrm{ppm})$. The yield of product (3) reached up to $36 \%$ after $1 \mathrm{~h}$ photoreaction even as its degradation occurred simultaneously (Figure S4). This indicated that hydroxyl-tribromobisphenol $\mathrm{A}$ was the main degradation intermediate during TBBPA photolysis.

From LC/MS results of photolysis products (detailed mass spectra of the transformation products were shown in Figures S5, S6, and S7), there were several substances observed only under air or $\mathrm{N}_{2}$ conditions. For example, products $(6),(7)$, and (8) were found only in air-saturated solution, indicating that they were produced by $\mathrm{O}_{2}$-dependent oxidation. In deoxygenated solution, product (5) was observed as the new photoproduct due to further reductive debromination of product (2). Products (3) and (4) were observed in both aerated and deaerated conditions. Both the high yield and UPLC chromatograms indicated product (3) was the main photolysis product of TBBPA in both air and $\mathrm{N}_{2}$ atmosphere. Therefore, we propose that the reaction pathway is independent of oxygen and related to $\mathrm{H}_{2} \mathrm{O}$.

Stable Isotope Analysis of Photoreaction of TBBPA. To confirm the hypothesis, stable isotope technique involving $\mathrm{H}_{2}{ }^{18} \mathrm{O}$ and ${ }^{13} \mathrm{C}$ was introduced. To elucidate formation pathways in phototransformation system, TBBPA were dissolved in labeled $\mathrm{H}_{2}{ }^{18} \mathrm{O}$ in place of normal $\mathrm{H}_{2} \mathrm{O}$. It is anticipated that hydroxylated products formed in oxygen isotope labeled systems $\left({ }^{16} \mathrm{O}_{2} / \mathrm{H}_{2}{ }^{18} \mathrm{O}\right)$ should have different ion peaks if ${ }^{18} \mathrm{O}$ participate in this photodegradation reaction.

The isotopic mass spectra of product (3) in normal $\mathrm{H}_{2} \mathrm{O}$ and $\mathrm{H}_{2}{ }^{18} \mathrm{O}$ solutions are shown in Figure 4. In nonlabeled experiments, the molecular ion peaks of product (3) were $477.08,478.92,480.75$, and 483.00 , owing to natural isotopes of $\mathrm{Br}, \mathrm{C}$, and $\mathrm{H}$ elements. If ${ }^{18} \mathrm{O}$ material were involved in this reaction, the molecular ion peaks would shift to higher ones (for example, $m / z 477.08$ would shift to $m / z 477.08+2 n, n=$ $1,2,3)$. As expected, the isotopic labeled experiment showed that the molecular ion peaks of product (3) shifted to $\mathrm{m} / \mathrm{z}$ 
Table 1. Summary of Intermediate Products Identified by LC/MS

\begin{tabular}{|c|c|c|c|c|c|}
\hline No. & Compounds[abbreviation] & $\begin{array}{l}\mathrm{Rt} / \\
\min \end{array}$ & $\mathrm{m} / \mathrm{z}$ & Formula & Structure formula \\
\hline 1 & $\begin{array}{c}\text { tetrabromobisphenol A } \\
\text { [TBBPA }]\end{array}$ & 15.7 & 542.7 & $\mathrm{C}_{15} \mathrm{H}_{12} \mathrm{Br}_{4} \mathrm{O}_{2}$ & \\
\hline 2 & $\begin{array}{c}\text { 2,6-dibromo-4- } \\
\text { [1-(3-bromo-4-hydroxyphenyl) } \\
\text {-1-methylethyl]-Phenol } \\
\text { [TriBBPA] }\end{array}$ & 11 & 463.09 & $\mathrm{C}_{15} \mathrm{H}_{13} \mathrm{Br}_{3} \mathrm{O}_{2}$ & \\
\hline 3 & $\begin{array}{c}\text { 2,6-dibromo-4- } \\
{[1 \text {-(3-bromo-4,5-dihydroxyphenyl) }} \\
\text {-1-methylethyl]-Phenol } \\
\text { [hydroxyl-tribromobisphenol A] }\end{array}$ & 8.5 & 479.09 & $\mathrm{C}_{15} \mathrm{H}_{13} \mathrm{Br}_{3} \mathrm{O}_{3}$ & \\
\hline 4 & $\begin{array}{l}\text { 2,6-dibromo-4-[1-(3,4,5-trishydroxyphenyl } \\
\text { )-1-methylethyl]-Phenol or } \\
\text { 2-bromo-6-hydroxyl-4-[1-(3-bromo-4,5-di } \\
\text { hydroxyphenyl)-1-methylethyl]-Phenol }\end{array}$ & 6.2 & 415.9 & $\mathrm{C}_{15} \mathrm{H}_{14} \mathrm{Br}_{2} \mathrm{O}_{4}$ & \\
\hline 5 & $\begin{array}{c}\text { 2,6-dibromo-4- } \\
\text { (2-(4-hydroxyphenyl)propan-2-yl)phenol } \\
\text { or } \\
\text { 4,4'-(propane-2,2-diyl)bis(2-bromophenol) } \\
{[\text { BiBBPA] }}\end{array}$ & 6 & 385.03 & $\mathrm{C}_{15} \mathrm{H}_{14} \mathrm{Br}_{2} \mathrm{O}_{2}$ & \\
\hline 6 & $\begin{array}{l}\text { 4-(2-hydroxyisopropyl)- } \\
\text { 2,6-dibromophenol }\end{array}$ & 4.7 & 307.9 & $\mathrm{C}_{9} \mathrm{H}_{10} \mathrm{Br}_{2} \mathrm{O}_{2}$ & \\
\hline 7 & 4-isopropylene-2,6-dibromophenol & 4.6 & 289.8 & $\mathrm{C}_{9} \mathrm{H}_{8} \mathrm{Br}_{2} \mathrm{O}$ & \\
\hline 8 & $\begin{array}{c}\text { 2,6-dibromophenol } \\
{[2,6-\mathrm{DBP}]}\end{array}$ & 4.23 & 251.2 & $\mathrm{C}_{6} \mathrm{H}_{4} \mathrm{Br}_{2} \mathrm{O}$ & $\mathrm{Br}^{\prime}$ \\
\hline
\end{tabular}

480.95, 483.10, 484.83, and 486.97 in $\mathrm{H}_{2}{ }^{18} \mathrm{O}$, which undoubtedly proved that $\mathrm{H}_{2}{ }^{18} \mathrm{O}$ participated in the formation pathway of product (3) during photolysis of TBBPA. In addition, it confirmed that the hydroxyl group replacement of bromine in product (3) came from a water molecule. The experiment results clearly explained why product (3) was detected in both air and $\mathrm{N}_{2}$ conditions. However, it is difficult to explain why the $2 n=4$ but not 2 or 6 , as the main product was hydroxyl-tribromobisphenol $\mathrm{A}$. One possible explanation is that oxygen exchange between $\mathrm{H}_{2}{ }^{18} \mathrm{O}$ and catechol oxygen in hydroxyl-tribromobisphenol A occurred. However, oxygen exchange between $\mathrm{H}_{2}{ }^{18} \mathrm{O}$ and the phenolic oxygen of hydroxyl-tribromobisphenol A did not proceed. It is wellknown that phenols can undergo enol-keto tautomerization to yield the less favorable keto form. The keto tautomer may react further with water to yield the ketal structure in some cases, which results in the exchange of ${ }^{18} \mathrm{O}$ in water with ${ }^{16} \mathrm{O}$ of phenolic oxygen atom. However, such an oxygen exchange reaction occurred in the compound containing the catechol moiety but not containing the phenolic moiety. ${ }^{32}$ It is suggested that adjacent oxygen atoms of the catechol facilitated in some manner the formation of the ketal species. In aqueous solution, the water molecule is hydrogen bonding to one of the catechol oxygens in a position close to the adjacent oxygen atom for nucleophilic attack and formation of the ketal structure, which would lower the activation energy necessary to form the ketal structure and facilitate the oxygen exchange. ${ }^{32}$

Compound-specific isotope analysis (CSIA) of ${ }^{13} \mathrm{C}$ offers new avenues for characterizing transformation pathways of organic contaminants. The isotopic fractionation during the 


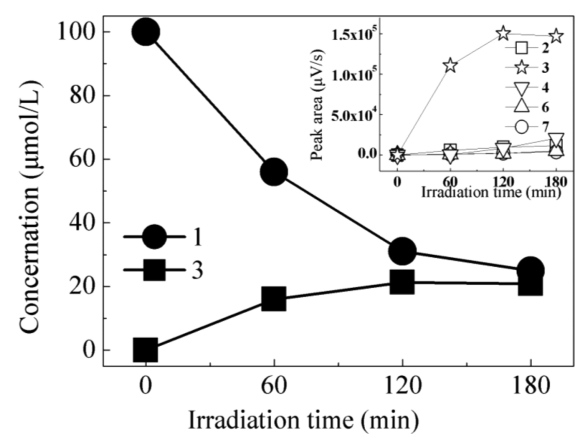

Figure 3. Concentration of TBBPA and it photolysis products (insert was the UPLC peak areas) under air atmosphere during $3 \mathrm{~h}$ of irradiation $(\mathrm{pH}=8.0)$.

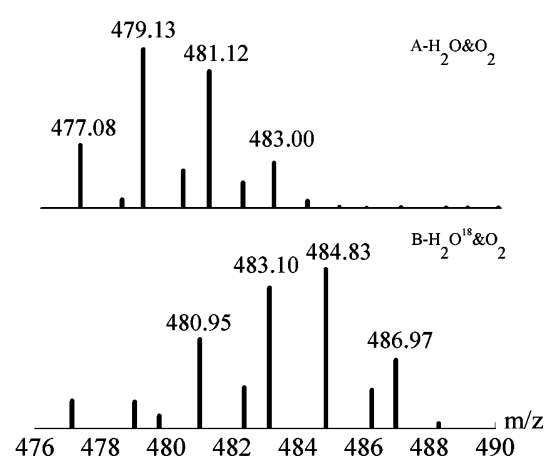

Figure 4. Mass spectra of product (3) produced during the photolysis of TBBPA in (A) $\mathrm{H}_{2} \mathrm{O}$ and (B) $\mathrm{H}_{2}{ }^{18} \mathrm{O}$.

photolysis process was measured based on carbon isotopic composition of the reacting compounds at different intervals of the degradation. The Rayleigh equation was used to establish the relationship between the change of isotopic composition and degree of degradation. ${ }^{33,34}$ The key to this concept is to determine the kinetic isotope effect (KIE) and apparent kinetic isotope effect (AKIE) derived from $\varepsilon$, which is bulk (i.e., average of the whole compound) isotope enrichment factor. The relative abundance of the heavy $\left({ }^{13} \mathrm{C}\right)$ and light $\left({ }^{12} \mathrm{C}\right)$ isotopes is determined in molecules of a given compound, expressed by the ratio $R={ }^{13} \mathrm{C} /{ }^{12} \mathrm{C} \cdot R_{\mathrm{c}, t}$ and $R_{\mathrm{c}, 0}$ are the ${ }^{13} \mathrm{C} /{ }^{12} \mathrm{C}$ ratios in TBBPA at time $t$ and time zero, respectively, and $f$ in eq 1 is the remaining fraction of (total) TBBPA at time $t$.

$$
\ln \left(\frac{R_{\mathrm{c}, t}}{R_{\mathrm{c}, 0}}\right)=\frac{\varepsilon}{1000} \times \ln f
$$

KIE and AKIE can be calculated as

$$
\begin{aligned}
& \mathrm{KIE}=\frac{1}{1+\frac{\varepsilon}{1000}} \\
& \mathrm{AKIE}=\frac{1}{1+\frac{Z \times n}{x} \times \frac{\varepsilon}{1000}}
\end{aligned}
$$

where $Z$ is the number of chemically equivalent reactive positions, $n$ is the number of atoms of element $C$ inside an organic compound, and $x$ is the number of atoms of element $\mathrm{C}$ that are located in reactive positions.

The resulting factors calculated using eqs $1-3$ are shown in Figure 5, Figure S8, and Table S2. Rose bengal sensitized photooxidation showed an inverse isotope fractionation with $\mathrm{C}$ AKIE of $0.9821 \pm 0.0009$. TBBPA photolysis without RB in air and $\mathrm{N}_{2}$ atmosphere resulted in inverse isotope fractionation with C-AKIE of $0.9678 \pm 0.0030$ and $0.9525 \pm 0.0032$, respectively. Formation of both reductive debromination product (2) and hydrolysis product (3) may contribute to the inverse isotope fractionation. We strongly believe that formation of product (3) is the main mechanism of the inverse isotope fractionation because it is the predominant photolysis product of TBBPA as shown in the Figure 3 inset. Reductive
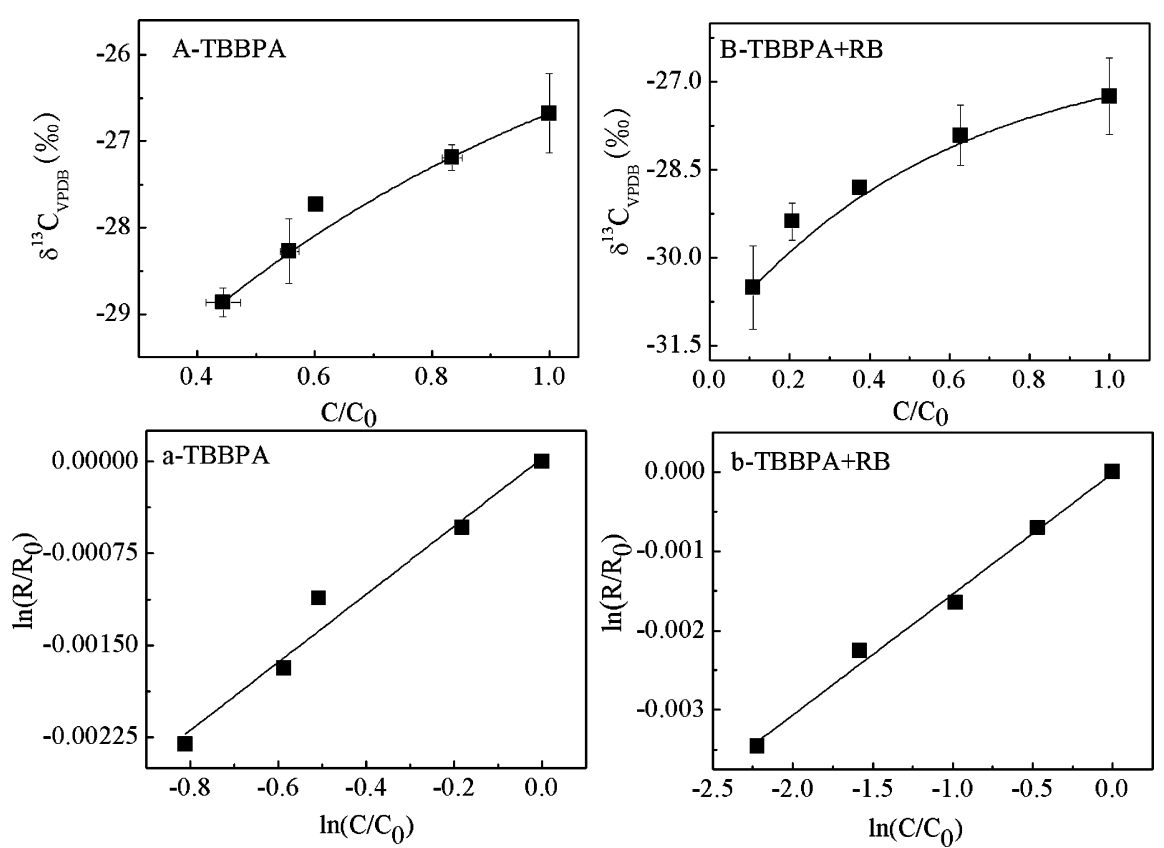

Figure 5. Isotope fractionation during TBBPA photolysis. Panels $\mathrm{A}$ and $\mathrm{B}$ show the evolution of $\delta^{13} \mathrm{C}$ values vs remaining fraction of TBBPA. Panels $\mathrm{a}$ and $\mathrm{b}$ show the linearized isotope enrichment used to derive enrichment factors in eq 1 . A and a are photolysis of TBBPA in aqueous solutions. $\mathrm{B}$ and $b$ are photolysis of TBBPA with rose bengal with an optical filter $(\lambda>400 \mathrm{~nm})$ in aqueous solutions. 


\section{Scheme 1. Proposed TBBPA Photolysis Pathways}

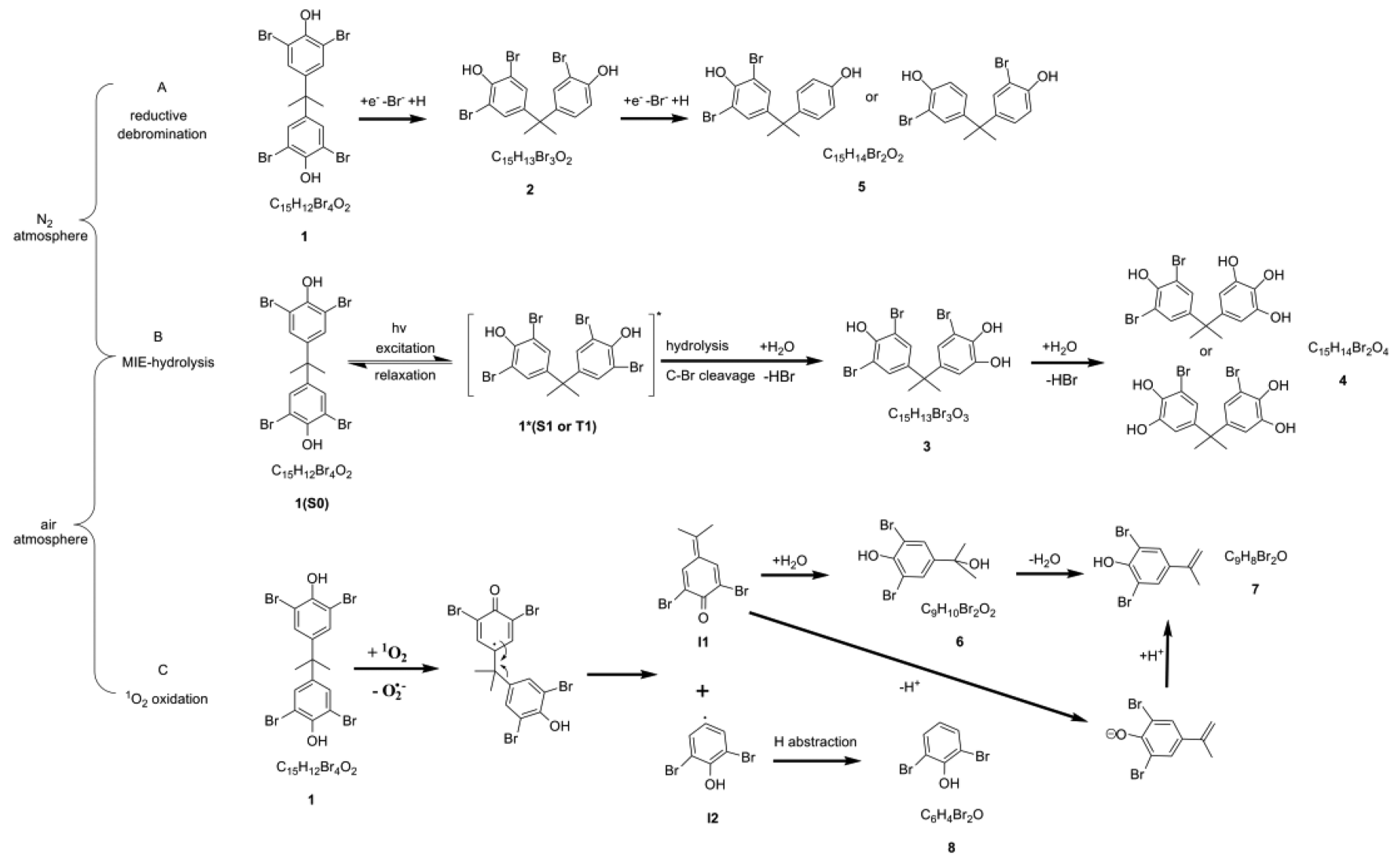

debromination can hardly be the main cause of the inverse isotope fractionation considering the low concentration of debromination product (2). The C-AKIE in air atmosphere was higher than that in $\mathrm{N}_{2}$ atmosphere but lower than that of $\mathrm{RB}$ sensitized oxidation, which also proved that TBBPA acted as a singlet oxygen sensitizer and caused its own degradation. The inverse isotope fractionation was observed for ${ }^{13} \mathrm{C}$ and ${ }^{15} \mathrm{~N}$ during the direct photolysis of atrazine; however, no AKIE values were reported. ${ }^{33}$ The oxidation induced inverse isotope fractions for $\mathrm{N}$ (N-AKIE 0.992-0.999) during substituted anilines oxidation ${ }^{35}$ and for $\mathrm{Br}$ (Br-AKIE 0.9949-1.0000) during photolysis of brominated phenols ${ }^{36}$ were also reported.

MIE-Hydrolysis Mechanism of TBBPA. Many studies on the mechanisms of halogenated phenols photolysis have been published in the literature. ${ }^{37}$ 4-Halogenated phenols undergo photodegradation by a radical pathway accompanied by homolytic $\mathrm{C}-\mathrm{Br}$ bond cleavage, whereas 3-bromophenol reacts with an ionic mechanism that includes heterolysis of the $\mathrm{C}-\mathrm{Br}$ bond. ${ }^{38-40}$ Both $\mathrm{O}_{2}$ and $\mathrm{H}_{2} \mathrm{O}$ are possible oxygen sources of the photoproducts. Direct photolysis of 2-halogenated phenols results in the formation of catechol and cyclopentadienecarboxylic acid. ${ }^{40,41}$ The formation of cyclopentadienecarboxylic acid is thought to take place via a ring contraction mechanism, while catechol is thought to be produced by an excited singlet state nucleophilic displacement of halogen by water. As previously noted by Burrows et al. in their review, ${ }^{42}$ when both ortho and meta positions of phenol are substituted by a chlorine group, photohydrolysis and the photocontraction pathway are competitive.

If $\mathrm{C}-\mathrm{X}$ bond cleavage is the rate-limiting step, then the reaction should be accompanied by normal mass-dependent carbon isotope fractionation (enrichment of remaining substrate by heavier isotope), resulting in a normal AKIE > 1. However, both the TBBPA photolysis without rose bengal and rose bengal sensitized photooxidation resulted in the inverse ${ }^{13} \mathrm{C}$ fractionation. The Hofstetter group reported that the inverse nitrogen isotope effect during oxidation of anilines by $\mathrm{MnO}_{2}$ originated from the formation of a radical intermediate after one-electron oxidation and subsequent increase in $\mathrm{C}-\mathrm{N}$ bond strength. ${ }^{35}$ In some cases, photochemical reactions are accompanied by magnetic isotope effect (MIE) if the magnetic interactions between spin carrying nuclei and unpaired electrons of excited molecular radicals contribute to the lifetime of the intermediate species. ${ }^{33,36,43}$ For example, photoexcitation of an organic compound generates radical pairs in the singlet state; light isotopologue radical pairs might predominantly recombine, while heavy isotopologue pairs will undergo S-T conversion via hyperfine coupling and react to product. For the TBBPA photolysis without the rose bengal case, formation of a stronger bond to the reactive position $\mathrm{C}$ is unlikely due to the aromatic $\mathrm{C}$ and electron withdrawing properties of bromide. Therefore, another process preceding the hydrolysis step is likely responsible for the observed inverse ${ }^{13} \mathrm{C}$ isotope effect during the direct photolysis of TBBPA. We propose that the formation of product (3) is via the MIEhydrolysis pathway. In this case, any factor that affects the excited states of TBBPA would change its photolysis rate. In addition, the reason for the inverse ${ }^{13} \mathrm{C}$ fractionation for the $\mathrm{RB}$ sensitized photooxidation might be different from the TBBPA photolysis as indicated by different values of C-AKIE. The increased $\mathrm{C}-\mathrm{C}$ bond strength of the reaction intermediate explains the inverse isotope fractionation in $\mathrm{RB}$ sensitized photooxidation (Scheme 1-C). 
The natural water is rich in fulvic acid, $\mathrm{Cl}^{-}, \mathrm{SO}_{4}{ }^{2-}, \mathrm{NO}_{3}{ }^{-}$, $\mathrm{CO}_{3}{ }^{2-}$, and $\mathrm{Fe}^{3+}$. In general, the existence of fulvic acid and ferric and nitrate ions is beneficial for the formation of reactive oxygen species under photoirradiation. However, all these environmental substances had a slightly inhibited effect on the TBBPA photolysis, indicating that all these substances can function as the excited state quencher of TBBPA, see Figure S9, Figure S10, Table S3, and Table S4 and the related discussion. The function of inorganic anions as the excited state quencher of organic compounds in the photoreaction solution has been reported. $^{44}$

TBBPA Photolysis Pathways. By ${ }^{13} \mathrm{C}$ fractionation and $\mathrm{O}^{18}$ tracer investigation, the MIE-hydrolysis pathway of TBBPA photolysis was proposed and illustrated in Scheme 1-B. Photoexcitation of TBBPA generates radical pairs in the singlet state; light isotopologue radical pairs might predominantly recombine, while heavy isotopologue pairs will undergo S-T conversion via hyperfine coupling in TBBPA and hydrolysis to hydroxyl-tribromobisphenol A. Further transformation of hydroxyl-tribromobisphenol A to product (4) was observed, which may also proceed via the MIE-hydrolysis pathway.

Another photolysis process occurred in the presence of $\mathrm{O}_{2}$ resulting in the formation of single aromatic ring products. ${ }^{1} \mathrm{O}_{2}$ should be responsible for this reaction (Scheme 1-C). TBBPA absorbs photon energy to form an excited state, and subsequent quenching of excited singlet and triplet states by ground state molecular oxygen produces ${ }^{1} \mathrm{O}_{2}$. Reaction of ${ }^{1} \mathrm{O}_{2}$ and TBBPA initially generates a phenoxy radical, and then the latter undergoes $\mathrm{C}-\mathrm{C}$ scission and new $\mathrm{C}=\mathrm{C}$ formation, creating unstable intermediates $\mathrm{I} 1$ and radical $\mathrm{I} 2$. Then radical $\mathrm{I} 2$ turns into product (8) and I1 is hydrolyzed to form product (6), which loses one water molecule to form product (7). I2 may also directly form product (7) through deprotonation. This reaction pathway was verified using rose bengal as the ${ }^{1} \mathrm{O}_{2}$ photosensitizer, and the experiment result was consistent with this explanation. The fact that products $(6),(7)$, and (8) were not detected in the reaction with $\mathrm{NaN}_{3}$ also confirms Scheme 1-C. This pathway has been reported in the oxidative degradation of TBBPA by singlet oxygen. ${ }^{28,29}$

Debromination products (2) and (5) of TBBPA were formed under $\mathrm{N}_{2}$ atmosphere as identified by LC/MS (Scheme 1-A). The debromination products were also reported by others in different systems. Zhong et al. ${ }^{26}$ found the $\mathrm{C}-\mathrm{Br}$ bond of TBBPA was attacked by hydroxyl radicals generated in the heterogeneous UV/Fenton process, leading to the debromination products. However, the debromination of TBBPA often occurred in the reductive degradation of TBBPA $^{19}$ under $\mathrm{N}_{2}$ atmosphere (Scheme 1-A). The ROS analysis above showed that hydroxyl radicals in the present system had no significant effect on the TBBPA degradation. The product (2) was observed in both $\mathrm{N}_{2}$ and air atmosphere, while product (5) was found only in the $\mathrm{N}_{2}$ atmosphere. These results indicated that the debromination reaction was performed through a reductive pathway.

Environmental Significance. Brominated compounds such as TBBPA pose potential threats to an aqueous environment as endocrine disruptors. Understanding kinetics, mechanisms, and pathways of TBBPA degradation is a prerequisite for determining fate and behavior of this aquatic micropollutant in a natural environment. Our study demonstrated that photolysis of TBBPA in aqueous solutions occurred under simulated solar light irradiation both in air and $\mathrm{N}_{2}$ atmosphere. A comprehensive evaluation of the photo- transformation processes for the first time detected hydroxyltribromobisphenol A as direct photolysis products of TBBPA. MIE-hydrolysis, singlet oxygen oxidation, and reductive debromination were established as three possible pathways of TBBPA photodegradation, which resulted in different degradation products. Both MIE-hydrolysis and singlet oxygen oxidation pathways showed inverse ${ }^{13} \mathrm{C}$ fractionation. This study has demonstrated the usefulness of the stable isotope fractionation techniques together with degradation products analysis for determining phototransformation processes of TBBPA in the aquatic environment. Further research should be undertaken to determine whether such photolysis processes are specific for TBBPA or apply to other halogenated compounds.

\section{ASSOCIATED CONTENT}

\section{Supporting Information}

Additional details on experimental methods and results (UPLC chromatograms, inorganic effects, CSIA calculation, intermediates identification of LC/MS, FT-ICR-MS). The Supporting Information is available free of charge on the ACS Publications website at DOI: 10.1021/acs.est.5b00382.

\section{AUTHOR INFORMATION}

\section{Corresponding Author}

*Phone: 86-535-2109080. Fax: 86-535-2109000. E-mail: xfhu@ yic.ac.cn.

\section{Notes}

The authors declare no competing financial interest.

\section{ACKNOWLEDGMENTS}

Generous support by the National Natural Science Foundation of China (nos. 41076040 and 41230858) is acknowledged.

\section{REFERENCES}

(1) WHO, Environmental Health Criteria, 172. Tetrabromobisphenol A and derivatives. In Environmental Health Criteria; Tetrabromobisphenol A and derivatives; WHO: Geneva, Switzerland, 1995; Vol. 172, 139pp.

(2) de Wit, C. A. An overview of brominated flame retardants in the environment. Chemosphere 2002, 46 (5), 583-624.

(3) Covaci, A.; Voorspoels, S.; Abdallah, M. A.-E.; Geens, T.; Harrad, S.; Law, R. J. Analytical and environmental aspects of the flame retardant tetrabromobisphenol-A and its derivatives. J. Chromatogr. A 2009, 1216 (3), 346-363.

(4) Arias, P. A. In brominated flame retardants-an overview. Second International Workshop on Brominated Flame Retardants, 2001; pp $14-16$.

(5) Suzuki, S.; Hasegawa, A. Determination of hexabromocyclododecane diastereoisomers and tetrabromobisphenol $\mathrm{A}$ in water and sediment by liquid chromatography/mass spectrometry. Anal. Sci. 2006, 22 (3), 469-474.

(6) Osako, M.; Kim, Y.-J.; Sakai, S.-i. Leaching of brominated flame retardants in leachate from landfills in Japan. Chemosphere 2004, 57 (10), 1571-1579.

(7) Johnson-Restrepo, B.; Adams, D. H.; Kannan, K. Tetrabromobisphenol A (TBBPA) and hexabromocyclododecanes (HBCDs) in tissues of humans, dolphins, and sharks from the United States. Chemosphere 2008, 70 (11), 1935-1944.

(8) Cariou, R.; Antignac, J.-P.; Zalko, D.; Berrebi, A.; Cravedi, J.-P.; Maume, D.; Marchand, P.; Monteau, F.; Riu, A.; Andre, F.; Le Bizec, B. Exposure assessment of French women and their newborns to tetrabromobisphenol-A: Occurrence measurements in maternal adipose tissue, serum, breast milk and cord serum. Chemosphere 2008, 73 (7), 1036-1041. 
(9) Jakobsson, K.; Thuresson, K.; Rylander, L.; Sjodin, A.; Hagmar, L.; Bergman, A. Exposure to polybrominated diphenyl ethers and tetrabromobisphenol A among computer technicians. Chemosphere 2002, 46 (5), 709-716.

(10) Thomsen, C.; Lundanes, E.; Becher, G. Brominated flame retardants in archived serum samples from Norway: a study on temporal trends and the role of age. Environ. Sci. Technol. 2002, 36 (7), $1414-1418$

(11) Huang, G. Y.; Ying, G. G.; Liang, Y. Q.; Zhao, J. L.; Yang, B.; Liu, S.; Liu, Y. S. Hormonal effects of tetrabromobisphenol A using a combination of in vitro and in vivo assays. Comp. Biochem. Physiol., Part C: Toxicol. Pharmacol. 2013, 157 (4), 344-351.

(12) Shi, H.; Wang, X.; Luo, Y.; Su, Y. Electron paramagnetic resonance evidence of hydroxyl radical generation and oxidative damage induced by tetrabromobisphenol A in Carassius auratus. Aquat. Toxicol. 2005, 74 (4), 365-371.

(13) Zhang, K.; Huang, J.; Zhang, W.; Yu, Y.; Deng, S.; Yu, G. Mechanochemical degradation of tetrabromobisphenol A: performance, products and pathway. J. Hazard. Mater. 2012, 243, 278-285.

(14) Feng, Y. P.; Colosi, L. M.; Gao, S. X.; Huang, Q. G.; Mao, L. Transformation and removal of tetrabromobisphenol A from water in the presence of natural organic matter via laccase-catalyzed reactions: reaction rates, products, and pathways. Environ. Sci. Technol. 2013, 47 (2), 1001-1008.

(15) Lin, K. D.; Liu, W. P.; Gan, J. Reaction of Tetrabromobisphenol A (TBBPA) with manganese dioxide: kinetics, products, and pathways. Environ. Sci. Technol. 2009, 43 (12), 4480-4486.

(16) Zhong, Y.; Peng, P. A.; Huang, W. Transformation of tetrabromobisphenol $\mathrm{A}$ in the presence of different solvents and metals. Chemosphere 2012, 87 (10), 1141-1148.

(17) Barontini, F.; Cozzani, V.; Marsanich, K.; Raffa, V.; Petarca, L. An experimental investigation of tetrabromobisphenol A decomposition pathways. J. Anal. Appl. Pyrolysis 2004, 72 (1), 41-53.

(18) Arbeli, Z.; Ronen, Z. Enrichment of a microbial culture capable of reductive debromination of the flame retardant tetrabromobisphenol-A, and identification of the intermediate metabolites produced in the process. Biodegradation 2003, 14 (6), 385-395.

(19) Ding, Y.; Zhu, L.; Wang, N.; Tang, H. Sulfate radicals induced degradation of tetrabromobisphenol A with nanoscaled magnetic $\mathrm{CuFe}_{2} \mathrm{O}_{4}$ as a heterogeneous catalyst of peroxymonosulfate. Appl. Cataly. B-Environ. 2013, 129, 153-162.

(20) Eriksson, J.; Rahm, S.; Green, N.; Bergman, A.; Jakobsson, E. Photochemical transformations of tetrabromobisphenol A and related phenols in water. Chemosphere 2004, 54 (1), 117-126.

(21) Zhang, J.; Wang, L. P.; He, S. L.; Hou, M. F.; Tian, L. J. Ozonation characteristics and kinetics of tetrabromabisphenol-A industry wastewater. J. China Univ. Mining \& Technol. 2011, 40 (3), 476-480.

(22) Horikoshi, S.; Miura, T.; Kajitani, M.; Horikoshi, N.; Serpone, $\mathrm{N}$. Photodegradation of tetrahalobisphenol-A $(\mathrm{X}=\mathrm{Cl}, \mathrm{Br})$ flame retardants and delineation of factors affecting the process. Appl. Catal, B 2008, 84 (3-4), 797-802.

(23) Guo, Y. G.; Lou, X. Y.; Xiao, D. X.; Xu, L.; Wang, Z. H.; Liu, J. $S$. Sequential reduction-oxidation for photocatalytic degradation of tetrabromobisphenol A: Kinetics and intermediates. J. Hazard. Mater. 2012, 241, 301-306.

(24) Guo, Y. N.; Chen, L.; Ma, F. Y.; Zhang, S. Q.; Yang, Y. X.; Yuan, X.; Guo, Y. H. Efficient degradation of tetrabromobisphenol A by heterostructured $\mathrm{Ag} / \mathrm{Bi}_{5} \mathrm{Nb}_{3} \mathrm{O}_{15}$ material under the simulated sunlight irradiation. J. Hazard. Mater. 2011, 189 (1-2), 614-618.

(25) Xu, J.; Meng, W.; Zhang, Y.; Li, L.; Guo, C. Photocatalytic degradation of tetrabromobisphenol $\mathrm{A}$ by mesoporous $\mathrm{BiOBr}$ : Efficacy, products and pathway. Appl. Catal., B 2011, 107 (3-4), $355-362$.

(26) Zhong, Y.; Liang, X.; Zhong, Y.; Zhu, J.; Zhu, S.; Yuan, P.; He, H.; Zhang, J. Heterogeneous UV/Fenton degradation of TBBPA catalyzed by titanomagnetite: Catalyst characterization, performance and degradation products. Water Res. 2012, 46 (15), 4633-4644.
(27) Pang, S. Y.; Jiang, J.; Yuan, G.; Zhou, Y.; Huangfu, X. L.; Liu, Y.; $\mathrm{Ma}$, J. Oxidation of flame retardant tetrabromobisphenol A by aqueous permanganate: reaction kinetics, brominated products, and pathways. Environ. Sci. Technol. 2014, 48 (1), 615-623.

(28) Han, S. K.; Bilski, P.; Karriker, B.; Sik, R. H.; Chignell, C. F. Oxidation of flame retardant tetrabromobisphenol A by singlet oxygen. Environ. Sci. Technol. 2008, 42 (1), 166-172.

(29) Han, S. K.; Sik, R. H.; Motten, A. G.; Chignell, C. F.; Bilski, P. J. Photosensitized oxidation of tetrabromobisphenol A by humic acid in aqueous solution. Photochem. Photobiol. 2009, 85 (6), 1299-1305.

(30) Chen, Y.; Hu, C.; Qu, J.; Yang, M. Photodegradation of tetracycline and formation of reactive oxygen species in aqueous tetracycline solution under simulated sunlight irradiation. J. Photochem. Photobiol., A 2008, 197 (1), 81-87.

(31) Draper, W. M.; Crosby, D. G. Photochemical generation of superoxide radical anion in water. J. Agric. Food Chem. 1983, 31 (4), 734-737.

(32) Clay, K. L.; Murphy, R. C. The exchange of $\left[{ }^{18} \mathrm{O}\right]-\mathrm{H}_{2} \mathrm{O}$ with the aromatic oxygen atoms of catecholamine metabolites. Biomed. Mass Spectrom. 1980, 7 (8), 345-348.

(33) Hartenbach, A. E.; Hofstetter, T. B.; Tentscher, P. R.; Canonica, S.; Berg, M.; Schwarzenbach, R. P. Carbon, hydrogen, and nitrogen isotope fractionation during light-induced transformations of atrazine. Environ. Sci. Technol. 2008, 42 (21), 7751-7756.

(34) Elsner, M.; Zwank, L.; Hunkeler, D.; Schwarzenbach, R. P. A new concept linking observable stable isotope fractionation to transformation pathways of organic pollutants. Environ. Sci. Technol. 2005, 39 (18), 6896-6916.

(35) Skarpeli-Liati, M.; Jiskra, M.; Turgeon, A.; Garr, A. N.; Arnold, W. A.; Cramer, C. J.; Schwarzenbach, R. P.; Hofstetter, T. B. Using nitrogen isotope fractionation to assess the oxidation of substituted anilines by manganese oxide. Environ. Sci. Technol. 2011, 45 (13), $5596-5604$.

(36) Zakon, Y.; Halicz, L.; Gelman, F. Bromine and carbon isotope effects during photolysis of brominated phenols. Environ. Sci. Technol. 2013, 47 (24), 14147-14153.

(37) Rayne, S.; Forest, K.; Friesen, K. J. Mechanistic aspects regarding the direct aqueous environmental photochemistry of phenol and its simple halogenated derivatives. A review. Environ. Int. 2009, 35 (2), 425-437.

(38) Lipczynska-Kochany, E. Direct photolysis of 4-bromophenol and 3-bromophenol as studied by a flash photolysis/HPLC technique. Chemosphere 1992, 24 (7), 911-918.

(39) Lipczynska-Kochany, E.; Bolton, J. R. Flash photolysis/HPLC method for studying the sequence of photochemical reactions: applications to 4-chlorophenol in aerated aqueous solution. $J$. Photochem. Photobiol., A 1991, 58 (3), 315-322.

(40) Boule, P.; Guyon, C.; Lemaire, J. Photochemistry and environment IV- photochemical behaviour of monochlorophenols in dilute aqueous solution. Chemosphere 1982, 11 (12), 1179-1188.

(41) Bonnichon, F.; Richard, C.; Grabner, G. Formation of an $\alpha$ ketocarbene by photolysis of aqueous 2-bromophenol. Chem. Commun. 2001, No. 1, 73-74.

(42) Burrows, H. D.; Ernestova, L. S.; Kemp, T. J.; Skurlatov, Y. I.; Purmal, A. P.; Yermakov, A. N. Kinetics and mechanism of photodegradation of chlorophenols. Prog. React. Kinet. 1998, 23 (1), 145-207.

(43) Buchachenko, A. L. MIE versus CIE: comparative analysis of magnetic and classic isotope effects. Chem. Rev. 1995, 95 (7), 25072528.

(44) Canonica, S.; Kohn, T.; Mac, M.; Real, F. J.; Wirz, J.; von Gunten, U. Photosensitizer method to determine rate constants for the reaction of carbonate radical with organic compounds. Environ. Sci. Technol. 2005, 39 (23), 9182-9188. 